\title{
Development of the Mine Geotechnical Risk Index
}

\author{
S Narendranathan GHD Pty Ltd, Australia \\ M Cheng GHD Pty Ltd, Australia
}

\begin{abstract}
The authors have developed the Mine Geotechnical Risk Index (MGRI), which has been advanced to attribute tolerable thresholds of risk in a given transitional mine closure context. This paper presents the philosophy behind the development of the MGRI using a conceptual case study and sets out how the authors propose it could be applied by practitioners in particular scenarios only when assessing tolerable thresholds of risk. The reader should note that this approach is not intended to replace conventional engineering risk assessments, it is merely an alternative method in evaluating the 'tolerability' of elevated risk thresholds.
\end{abstract}

Keywords: Probability of Failure, Factor of Safety, geotechnical risk index, slope stability, circular failure, coal sliding, acceptable risk, brown coal, pit lake, mine rehabilitation

\section{Introduction}

During the last two decades, there has been much focus within the mining industry on the quantification and management of mining-related hazards and corresponding risks and consequences. A particular focus for the authors has been to consider how geotechnical and mine stability related risk quantification has evolved in the mining industry since the 1980s and in particular, to identify areas which might benefit from clearer definition. This paper explores the following concepts:

- Conventional geotechnical risk evaluation processes are based on particular scenarios (i.e. an operational mine or a closed and rehabilitated scenario).

- An active mining operation is subjected to continuous risk management, i.e. should a risk manifest, it is typically addressed in a timely manner, and a rehabilitated mine would be subject to the relevant serviceability criteria, which may be governed by aspects such as proximity to public and associated infrastructure.

- Upon the cessation of mining and the transitioning of an operation into the rehabilitation and closure phases, a number of these active management protocols may cease, though there may also be a possible proportional reduction in risk exposure as well.

- As the operation enters this new phase, it is challenged with reduced revenues but still the requirement to safely transition the operation to its intended final rehabilitated landform, which may have a particular serviceability criteria associated with it, depending on the level of public exposure anticipated. The management of geotechnical risks during this period still needs careful consideration and can be challenging to attribute a serviceability criteria to, as it is neither 'operational' nor does it represent the final landform/exposure criteria.

The authors have explored a number of risk evaluation protocols as part of their research and put forward a process as will be outlined in this paper with the benefit of a conceptual case study which can be utilised during the transitional phase (i.e. upon the cessation of mining and prior to the establishment of the final landform to pragmatically and cost effectively tailor geotechnical management protocols).

The approach that has been put forward in this paper is not intended to be applied for the post-closure risk profile, which will need to be evaluated based on an objective and sound risk assessment. 


\subsection{Literature review}

A number of pioneering geotechnical practitioners such as Dight, Harr, McMahon and Lilly, have hitherto put forward various approaches for evaluating and quantifying risk in the context of geotechnical engineering (Call 1992; Chowdhury 1992; Harr 1977, 1987; Hoek \& Bray 1974; Hoek \& Brown 1997; Lilly 1982, 2000; Martin \& Piteau 1978; McMahon 1985; Xu \& Chowdhury 1999; Xu et al. 2000). The reader is directed to the list of references to review and appreciate the early development of quantitative risk assessment approaches pioneered by these practitioners.

The authors also note that the Risk Management chapter (Brown \& Booth 2009) in the CSIRO's Open Pit Design Guidelines provides mining geotechnical practitioners with a number of useful risk evaluation protocols and quantification algorithms that can be readily applied in operational and closed or rehabilitated mining scenarios.

These methodologies typically assess the associated consequences of a potential pit failure and align the outcomes with suitable numerical stability analysis techniques. These techniques are acknowledged as robust and have indeed been espoused extensively by geotechnical practitioners.

\subsection{Definition of problem}

Prevailing geotechnical risk evaluation approaches are considered to be typically suitable for addressing a particular category of risk scenarios for a given set of hazards. For instance, during the course of a mine's operation, the consequences associated with a potential pit wall failure can be directly attributed to the cost of the clean-up and/or the reinstatement of compromised infrastructure where applicable.

In such a context, one appreciates that the operation has a particular planned mine life and the consequence associated with an unplanned pit slope failure can be factored or amortised over the life of the mine, depending on the size of the failure, and it can be annualised thereafter. However, it is the authors' contention that such a process of amortisation cannot be applied to a mine in closure as there is not likely to be an active revenue stream.

The question arises, during the transient state (i.e. upon the cessation of mining and prior to the final rehabilitated landform being established), how does one objectively evaluate the operations risk considerations? i.e. does it adhere to an operational or a rehabilitated scenario?

In the authors' opinion, this has been a potential gap in a number of existing risk evaluation processes, and there can be challenges associated with applying conventional risk evaluation approaches in the 'transient' serviceability context of a mine transitioning from the active operational to the rehabilitation and closure phases.

Accordingly, the authors are advancing an approach in this paper that has been developed to attribute 'acceptable' increases of tolerable risk thresholds based on research conducted by Bell et al. (2005) on landslides which may be applied during this transient phase. It should be noted that the authors do not intend this approach to be extended to the post-closure phase, which must be based on a sound engineering risk assessment.

\section{Methodology}

As stated previously, there are a number of existing practitioners that have put forward approaches for evaluating absolute states of risk given a particular operational context or scenario. In their pursuit of developing the Mine Geotechnical Risk Index, henceforth referred to as the MGRI, the authors have chosen to utilise the fundamentals of an approach put forward by Lilly (2000) which was subsequently updated by Narendranathan (2009). The approach put forward originally by Lilly involved assessing the Probability of Failure (Pf) for a given mine domain or section, then evaluating the consequence of a failure. Lilly attributed the calculated volume of potential material movement (failure) as the consequence associated with a given slope instability. 
For instance, in the scenario of a simple circular failure (as outlined in Figure 1), it is possible to calculate the Factor of Safety using the Bishop or Morgenstern-Price methods. These calculations will yield a critical slip surface. This surface will have a particular cross-sectional area; in this case it is $55 \mathrm{~m}^{3} / \mathrm{m}$.

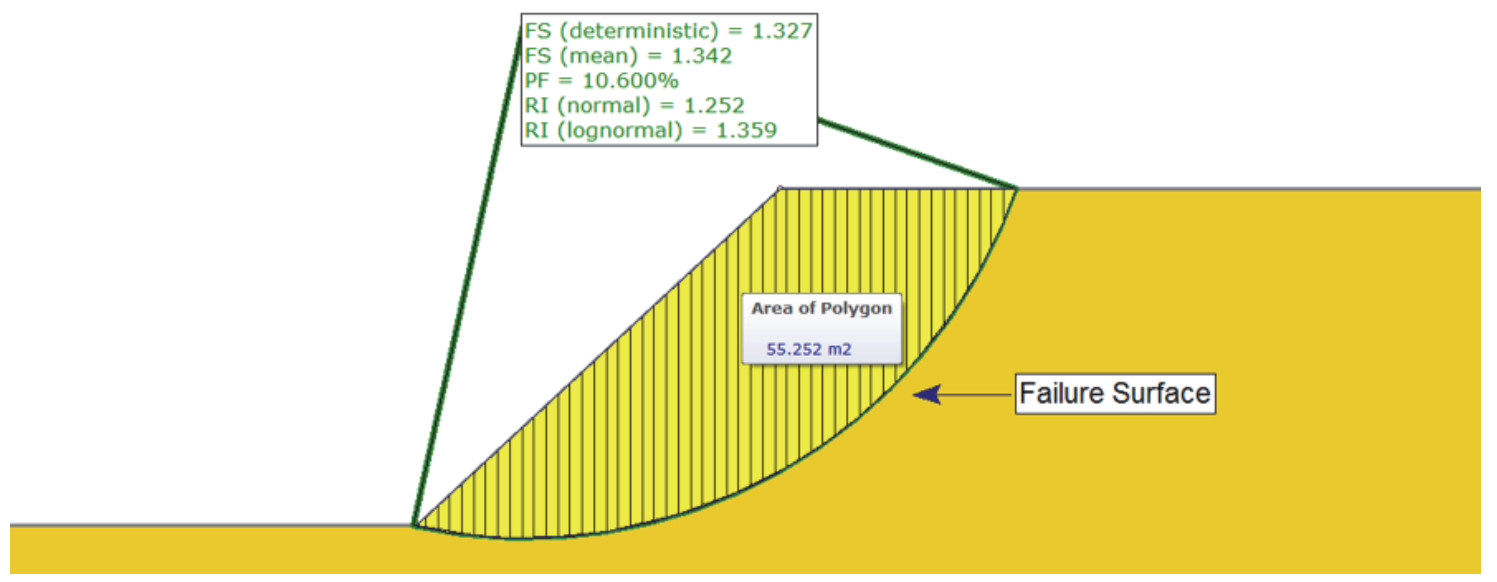

Figure 1 Simple circular failure mechanism

The approach outlined by Narendranathan (2009) can be used to characterise the variability of the in situ materials associated with the soil or weak rock mass being subjected to the aforementioned stability calculations to determine the reliability associated with the calculated Factor of Safety (FS), i.e. the PF.

The approach put forward by Lilly involves calculating a 'consequence' rating which was defined as:

$$
P F \times V F
$$

where:

$$
\begin{aligned}
& \mathrm{PF} \quad=\text { Probability of Failure. } \\
& \mathrm{VF} \quad=\text { Volume of Failure (or possible material movement), i.e. Consequence of Failure. }
\end{aligned}
$$

In the case of the example in Figure 1, this would be:

$$
10.6 \% \times 55.252 \mathrm{~m}^{3} / \mathrm{m}=5.86
$$

This particular metric for this domain can then be compared with that calculated for adjacent or other domains within the same mine. In essence, the higher this number, the higher the consequence associated with a potential slope failure. Hence suitable and comparatively more robust management protocols can be employed within areas of the mine where this metric returns a higher value (i.e. this approach provides an objective methodology to tailoring geotechnical management effort in certain 'high risk' areas of the operation).

However upon the cessation of mining activities, the corresponding reduction in exposure of mine personnel to a potential slope failure diminishes significantly. In such situations, employing a philosophy of 'exclusion' to manage the risk of a slope failure affecting members of the public is generally accepted as a suitable approach.

In the Latrobe Valley region of Victoria, most coal mines are located in close proximity to several facets of public infrastructure, council roads, state highways and townships to name a few. In such a scenario, mine and geotechnical engineers may plan a final (rehabilitated) landform which may include a full pit lake that has been designed to meet the requisite legislative requirements in relation to being 'safe and stable'.

However the final landform and full pit lake may take decades to achieve. This results in what is effectively a dynamic environment with a number of challenges that need to be managed (i.e. the recovery of aquifer pressures may alter the effective stress parameters for critical geological units facilitating a drop in effective strength potentially leading to an increased likelihood of slope instability). 
A mere policy of exclusion may not always suffice, or even be objectively defensible from a technical standpoint, particularly when it has the potential to impact on members of the public, if the extent of a potential failure is not carefully quantified (i.e. to verify the efficacy of the nominated exclusion process and its extent). Additionally it should be considered that the operation now does not have an active revenue stream, and will therefore need to tailor its geotechnical management efforts within the domains that are likely to pose the most risk to the public, be it personnel or infrastructure, during the 'transient' rehabilitation phase, prior to enacting the final landform. It is the consideration of these points that led the authors to consider the approach employed by practitioners in the landslide hazard management field; most notably Bell et al. (2005).

Accordingly in developing the subject metric of this paper, the MGRI, the authors considered not only the likelihood and potential volume of a slope instability, which is derived from the PF, but also the potential for this failure to impact on proximate public infrastructure and the likelihood of affecting members of the public, after Bell et al. (2005).

The authors have defined the MGRI thus:

$$
M G R I=\left(P C_{t} \times C_{f} \times I_{f} \times S_{f}\right)
$$

where:

$$
\begin{aligned}
& \text { MGRI = Mine Geotechnical Risk Index. } \\
& C_{f}=\text { Consequence Factor }- \text { Probability of Failure (PF) } \times \text { Volume of Failure (VF). } \\
& \mathrm{PC}_{t}=\text { Annual probability of the primary instability load or scenario occurring. } \\
& \mathrm{I}_{f}=\text { Impact factor. } \\
& \mathrm{S}_{\mathrm{f}}=\text { Seasonal factor. }
\end{aligned}
$$

It is important to note that the application of the MGRI is not intended to replace an engineering risk assessment process; it is primarily put forward as an approach to provide practitioners with a tool to comparatively assess elevations in risk profiles during the mine's rehabilitation phase only (i.e. it is not intended to reflect the postclosure risk profile, which will need to be based on an objective and sound risk assessment).

In applying Equation 3 in calculating the resulting risk, the authors provide the following guidance in selecting/calculating the respective factors outlined above.

- $C_{f}$ - consequence factor.

PF $\times$ VF, after Lilly (2000) and Narendranathan (2009), as per the calculation process outlined above.

- $\mathrm{PC}_{\mathrm{t}}-$ annual probability of the primary instability load or scenario occurring.

This factor is best applied where there is a documented history of a particular loading scenario or event occurring that leads to instability, without which it is contingent upon a clear understanding of site instability mechanisms and causative factors.

Take a scenario where the primary destabilising force for a particular slope is the elevation of the phreatic head and associated gradient within it and that this is managed by dewatering bores maintaining the gradient at a particular (stable) level. Let's also assume that there is an onsite history of these dewatering bores malfunctioning once every three years. This would mean that that this factor is 0.33 (i.e. 1/3). 
- If - impact factor.

The impact factor is attributed based on the potential for a single 'event' to impact multiple individuals. The following criteria is proposed:

- Single event impacting 1 individual, $\mathrm{I}_{\mathrm{f}}=0.15$.

$\circ$ Single event impacting $>1<3$ individuals, $\mathrm{I}_{\mathrm{f}}=0.5$.

- Single event impacting $>3<6$ individuals, $\mathrm{I}_{\mathrm{f}}=0.7$.

- Single event impacting $>6$ individuals, $I_{f}=1.0$.

- $\mathrm{S}_{\mathrm{f}}$ - seasonal factor.

This is a factor attributed in proportion to the likelihood of a nominated seasonal event occurring in the nominated period. For example, say the proposed period of mine rehabilitation is 20 years and let's assume the critical event that might trigger an instability by elevating the phreatic gradient within a slope is a 1 in 50 year event. This factor would be calculated thus, 20/50 $=0.4$.

For example, in our hypothetical scenario (Figure 1), the MGRI would be evaluated thus, assuming an instability would impact $>6$ members of the public:

$$
\text { MGRI }=5.86 \times 0.33 \times 1.0 \times 0.4=0.774
$$

\subsection{Acceptable risk}

In determining how the MGRI can be applied, one needs to consider what an appropriate level of risk is, in a nominated setting. The prevailing concept applied by most practitioners is the 'As Low as Reasonably Possible' (ALARP) concept after Australian Geomechanics Society (2000), Glade et al. (2005), Lee and Jones (2004), and IUGS Working Group on Landslides - Committee on Risk Assessment (1997).

Bell et al. (2005) note in their paper that the definition of 'acceptable risk' is rather a complex and subjective aspect. At times, it can be fraught with subjectivity and public perception which can lack objective technical substantiation. As most mining geotechnical practitioners are generally appreciative of this aspect, the authors have not delved into a detailed discussion on these aspects in this paper. However, the reader is referred to Bell et al. (2005) should they be interested in finding out more.

The key point that Bell et al. state in their paper, is that conventional (geotechnical) risk evaluation concepts at times lack the recognition of an overview on protection deficits for larger areas (i.e. the scale of impact for a large scale mine slope instability may be significantly larger than say a single rock dislodging from a slope face and falling onto a roadway below). Additionally, risk must always be considered in the temporal scale, as opposed to assuming it is always present like a number of the contemporary risk evaluation protocols assume.

These are crucial concepts to consider when developing risk treatment protocols so as to ensure that they remain appropriate and are cost effective; the latter being a particular consideration for mines that are in the closure phase, void of a revenue. These considerations have formed the basis of the risk criteria proposed by the authors as will be employed in the case study.

\subsection{Definition of tolerable risk increase}

For the purposes of this paper, the authors have chosen to define the thresholds of tolerable risk increases as summarised in Table 1. The percent increases have been classified into three categories - low, medium and high, respectively. These criteria were selected based on the guidance provided by a number of authors (Ammann 2005; Ágústsson et al. 2003; Borter 1999; Geotechnical Engineering Office 1997; Jónasson et al. 1999; Jóhannesson \& Ágústsson 2002; Malone 2005; The Ministry of the Environment 2000), on the topic of 'acceptable levels of risk' when considering landslide areas that are subjected to public access. 
Table 1 Risk increase thresholds

\begin{tabular}{ll}
\hline Risk level & Threshold of variation \\
\hline Very low & $\leq 0 \%$ \\
Low & $0-13 \%$ \\
Medium & $13-29 \%$ \\
High & $>29 \%$ \\
\hline
\end{tabular}

Notwithstanding the information summarised within Table 1 , the authors strongly caution against the application of these thresholds without the benefit of a detailed site-specific risk assessment and consultation with all involved stakeholders. These thresholds are proposed as starting points only in line with observations made by Bell et al. (2005), and may need refinement with the benefit of site-specific risk assessments.

\section{Case study}

For the purposes of demonstrating the application of the MGRI, the authors have considered a coal block sliding instability mechanism, as depicted in Figure 2, for a hypothetical mine entering the closure and rehabilitation phases of its operation. This is also the primary instability mechanism that is typically encountered in brown coal mines in the Latrobe Valley region of Victoria.

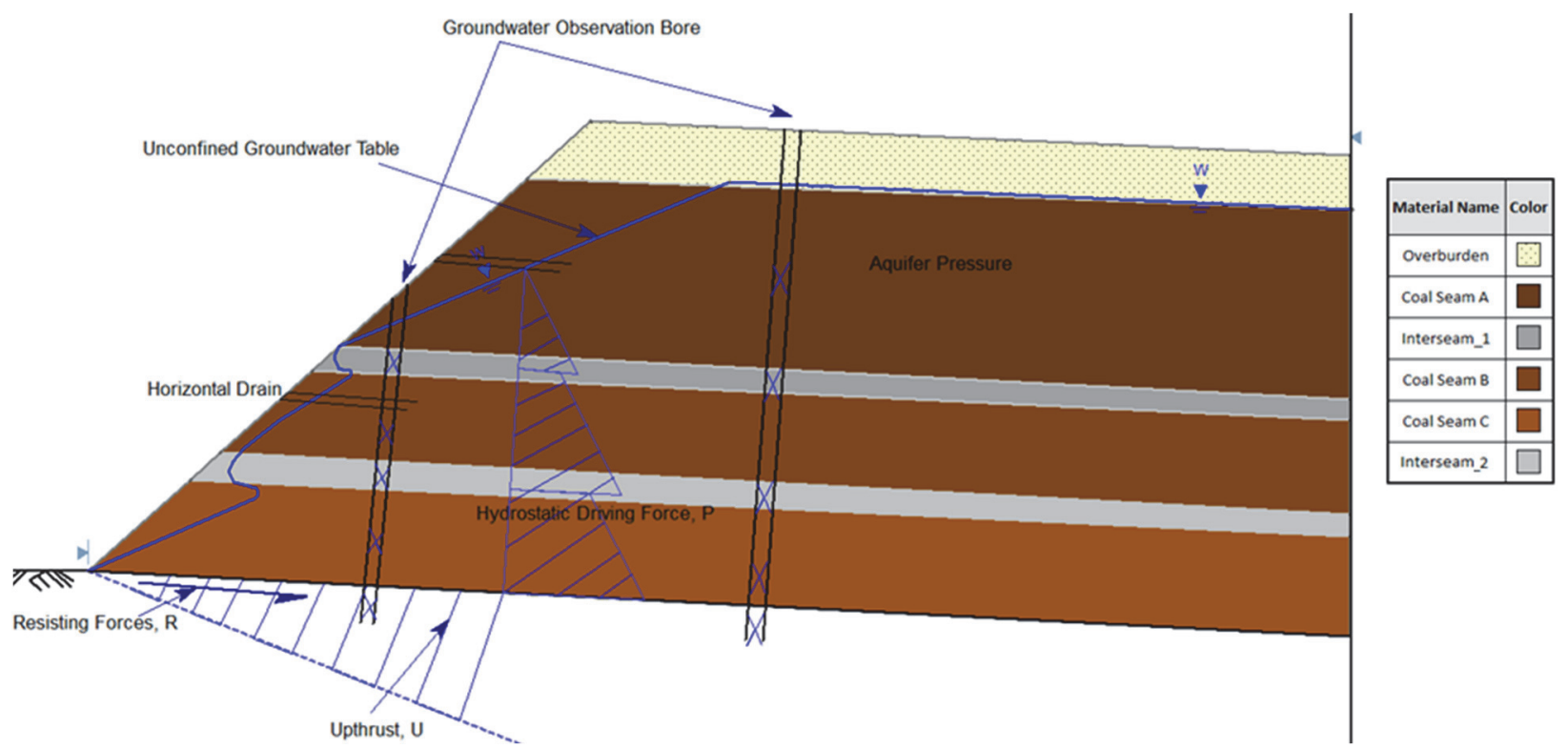

Figure 2 Schematic free body diagram of a coal block sliding mechanism

The primary factors governing the failure mechanics are generally:

- Hydrostatic driving force of water contained in the predominantly sub-vertical joints.

- The orientation of the joints which essentially define the geometry and volume of the potential block susceptible to sliding on the underlying clay interseams.

- Release of existing tectonic stresses by removal of coal within the mine.

- Shear strength and associated variability of the interseam sediments within and at the base of the coal seams.

- Porewater pressures within the interseams.

- Degree of strata dip in or out of the mine batter. 
The mechanism initiates when destabilising forces overcome resisting forces (interseam strength) which typically occurs when:

- Existing tectonic stresses are released by the progressive removal of coal within the mine void.

- The hydrostatic head of water in the near-vertical cracks in the coal seams rises to a critical level.

- In both cases, when the destabilising force is sufficient to cause shearing through the interseam layer, this manifests as block movement of the overlying sections of batter.

Initial block sliding movements can cease upon the release of tectonic stress and drop in joint water levels (hydrostatic driving head). Any recharge of the coal joints by surface water can trigger further movements. In these settings the initial block movement causes a significant loss in the interseam shear strength which then is deemed to be at residual strength level. This loss of strength means that the previously mobilised block becomes more susceptible to subsequent sliding events. Hence, by the time a mine has entered the closure phase, it would have likely undergone several such shear events on the underlying interseam at residual strength, leaving it quite susceptible to future movements, if not treated appropriately.

The manner in which the (re)mobilising of a potential block slide on the basal interseam is generally mitigated during the operational phase of such mines is via the installation of supplementary slope stabilisation measures thus:

- Toe buttresses to provide a counterweight against the destabilising forces.

- The installation of additional batter drainage measures to ensure that excessive driving heads do not develop within the coal joints.

Such measures typically provide an acceptable risk mitigation outcome, but rely heavily on active management, which is not always feasible in the context of a mine in the closure phase.

\subsection{Introduction to case study setting}

For the purposes of applying the MGRI process, the authors have considered a $1 \mathrm{~km}$ length of wall within the mine which consists of three 'risk sectors' shown in Figure 3, thus:

- Risk sector 1: This sector abuts a local council road. In consultation with the road designers, it was understood that the road could tolerate some degree of deformation, in the order of $\geq 100 \mathrm{~mm}$ prior to becoming unserviceable and could result in hazardous conditions for the users. Accordingly, the decision was made to employ some improvements to the slope to ensure it does not result in significant deformation. These measures where included ensuring that redundancy was built into the management of water gradients within the batters to ensure that the likelihood of achieving critical phreatic gradients within the batters is low, and to ensure that any batter movements remain within an acceptable range, which will be monitored with survey pins. Past campaigns of finite element modelling undertaken on this site attributed a FS of approximately 1.5 to 'stable' thresholds of deformation. The proposed slope improvement measures were to consist of the installation of an additional dewatering bore, coupled with a routine inspection program by caretaker personnel during the rehabilitation phase. These measures were put forward to ensure that the development, and more importantly the progression of tension crack that could compromise the road, are observed and suitable prophylactic measures employed in a timely fashion.

- Risk sector 2: This sector abuts a piece of commercial infrastructure that is highly intolerant to settlement or deformation to remain serviceable. A decision was therefore made to employ substantial improvements to the slope stability to ensure it performs as needed. These measures included installing a buttress along the critical areas of the slope (downdip) to provide additional confinement along the clay seam to effectively mobilise a higher degree of effective shear strength. In addition, supplementary dewatering horizontal bores would be installed to ensure that there is redundancy in the management of the phreatic gradient within the slope. The FS targeted was 2.0. 
- Risk sector 3: As the mine has ceased operation, there is unlikely to be a risk to personnel. Accordingly, there is a potential for this sector to tolerate a higher degree of risk during the transitional phase of mine closure. The approach selected here was one of tolerating an elevated risk profile, during the mine rehabilitation phase, noting that upon the completion of rehabilitation, all three sectors would be similarly aligned with respect to risk profiles to ensure that any long-term consequences of instability does not impede the future development of this land.

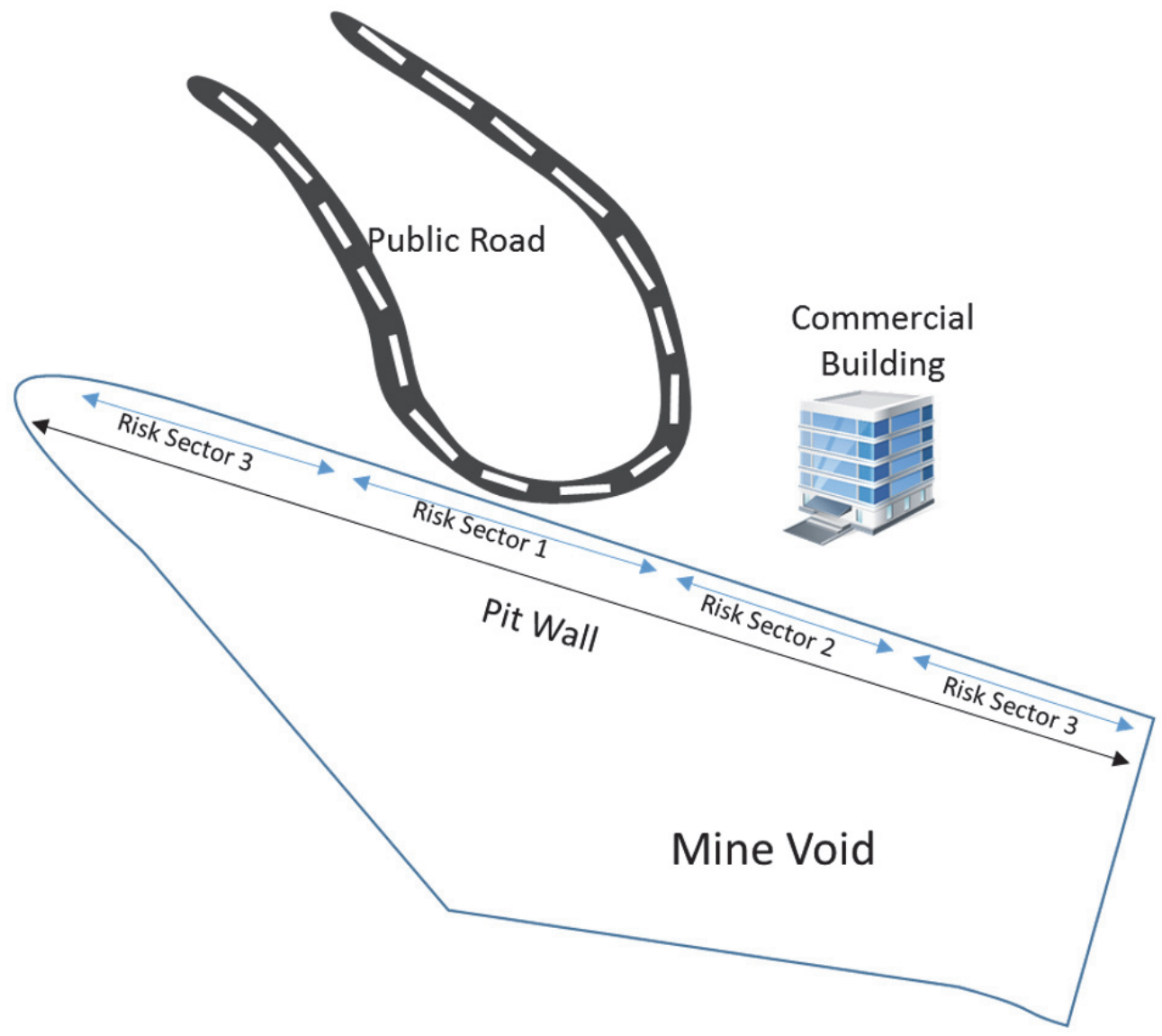

Figure 3 Schematic representation of the risk sectors

The following points should be noted regarding the operational history and closure requirements of the mine as they form material inputs in the MGRI calculation process:

- The rehabilitation and closure period has been planned to occur over 10 years, and includes a full pit lake to provide counter-balance to a potential block sliding failure(s).

- The site surface and subsurface drainage systems have been designed to cater for 1 in 20-year events, however requires routine and rigorous annual maintenance to ensure functionality.

- There is an operational history of critical dewatering pumps malfunctioning once every four years. Noting that the management of hydrostatic pressure within the coal joints and pore water pressure elevations within the underlying clay seams are the critical causative factors leading to instability.

The above outlined risk domains are not expressly indicative of the geotechnical domains. It should be noted that whilst the primary instability mechanism for this section of wall is the coal block sliding mechanism, there are subtle differences in the geological and geotechnical conditions (i.e. the dip, strength and mechanical characteristics (plasticity) of the underlying coal seam). These considerations give risk to geotechnical subdomains, each of which results in unique stability calculation results (i.e. FS and PF as well as failure geometry). 


\subsection{Application of the Mine Geotechnical Risk Index}

For the purposes of demonstration, the authors have chosen to solely focus on risk sector 2 as outlined in Figure 3 and its associated geotechnical subdomains. To this end the authors chose a representative geotechnical section within risk sector two and calculated the current stability parameters at the time of cessation of mining as outlined in Figure 4. Table 2, outlines the calculation of the corresponding MGRI value for this section at the cessation of mining activities, assuming that active management of geotechnical risk will continue.

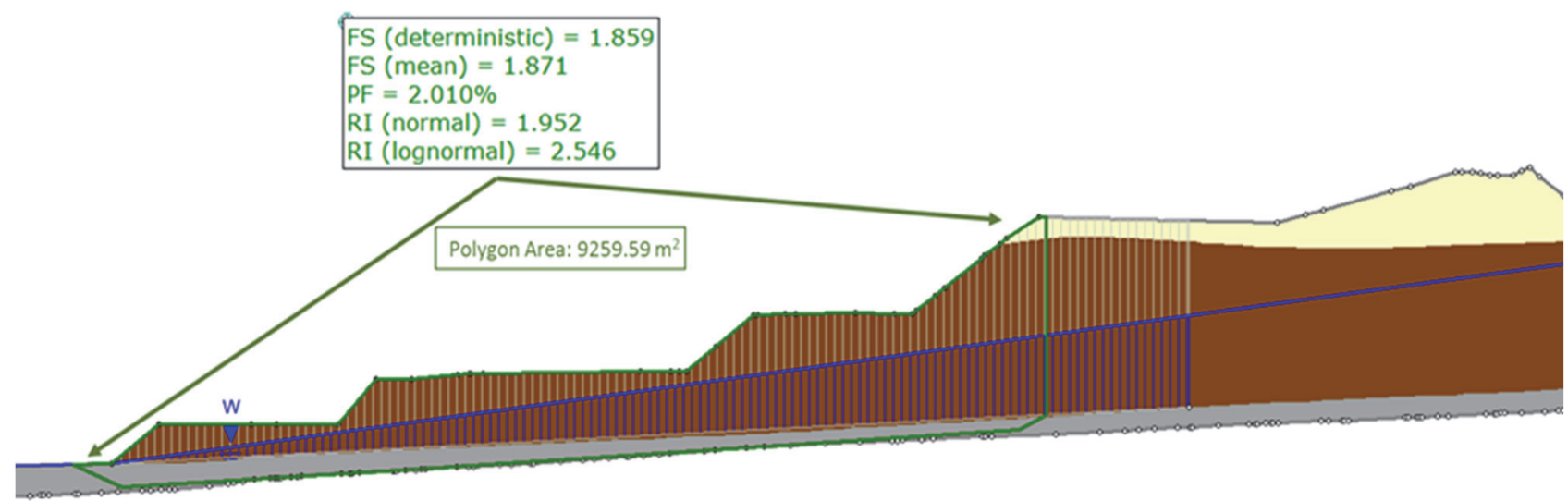

Figure 4 Stability calculations - risk sector 2

Table 2 Calculation of the Mine Geotechnical Risk Index at closure assuming geotechnical management continues - risk sector 2

\begin{tabular}{|c|c|c|}
\hline Parameters & All domains & Explanatory notes \\
\hline PF & $2.01 \%$ & Calculated PF (Figure 4) \\
\hline Area $\left(\mathrm{m}^{3} / \mathrm{m}\right)$ & $9,259.59$ & Cross-sectional area of critical failure (Figure 4) \\
\hline$C_{f}$ & 186.12 & Consequence factor ( $\mathrm{PF} \times$ area) \\
\hline$P C_{t}$ & 0.25 & $\begin{array}{l}\text { Based on an annualised probability of malfunctioning of the } \\
\text { dewatering infrastructure }\end{array}$ \\
\hline$I_{f}$ & 1.00 & $\begin{array}{l}\text { Assumption was that if the infrastructure arrangement } \\
\text { became unserviceable it could result in } 6+\text { fatalities }\end{array}$ \\
\hline$S_{f}$ & 0.05 & Annualised probability, designs based on 1 in 20 year event \\
\hline MGRI & 2.33 & 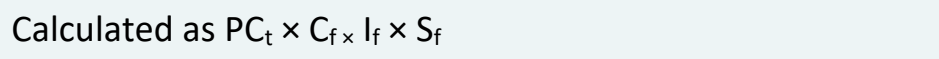 \\
\hline
\end{tabular}

Based on the calculations in Table 2, an MGRI of 2.32 has been calculated for this section, which can be considered the base case scenario. This value will serve as the metric against which comparative risk elevations will be assessed for the respective geotechnical domains within this risk.

Table 3 presents the calculated MGRI value for the same geotechnical section within risk sector two, assuming the termination of active geotechnical management. 
Table 3 Calculation of the Mine Geotechnical Risk Index at closure assuming geotechnical management ceases - risk sector 2

\begin{tabular}{lll}
\hline Parameters & All domains & Explanatory notes \\
\hline PF & $2.01 \%$ & Factors as Table 2 \\
Area $\left(\mathrm{m}^{3} / \mathrm{m}\right)$ & $9,259.59$ & \\
Cf & 186.12 & \\
PCt & 0.25 & \\
If & 1.00 & Annualised likelihood of drainage malfunction increases as \\
Sf & 0.5 & no maintenance is undertaken during the closure phase \\
& & \\
MGRI & 23.26 & \\
Delta & $900 \%$ increase in & \\
& risk rating & \\
\hline
\end{tabular}

Based on the calculations undertaken in Table 3, it can be seen that upon cessation of regular mine maintenance measures, in particular the maintenance of the drainage system, there is a theoretical (absolute) increase in the overall risk profile, to the tune of approximately $900 \%$. This increase in overall risk is well beyond acceptable tolerances put forward in Section 2.2 of this paper. This clearly demonstrates that leaving this sector of slope untreated during the closure period could result in less than satisfactory outcomes in relation to the containment of risks to within a tolerable threshold.

\subsection{Applying the Mine Geotechnical Risk Index process in tailoring the implementation of critical slope stabilisation measures}

The previous section outlined that the cessation of geotechnical management results in an unacceptable increase in risk, which requires the implementation of supplementary slope management measures. The measures under consideration were the installation of a buttress and additional slope drainage to manage the coal water gradient. Various iterations were considered and calculated (i.e. buttress design dimension and drainage considerations).

Outlined below in Figure 5, are the updated results of the stability calculations incorporating these measures. It can be seen that it results in an increase in the FS and reduction in failure volume in comparison to the base case scenario presented in Figure 4 . Table 4 presents the revised calculation of the MGRI for this section incorporating the slope stabilisation measures.

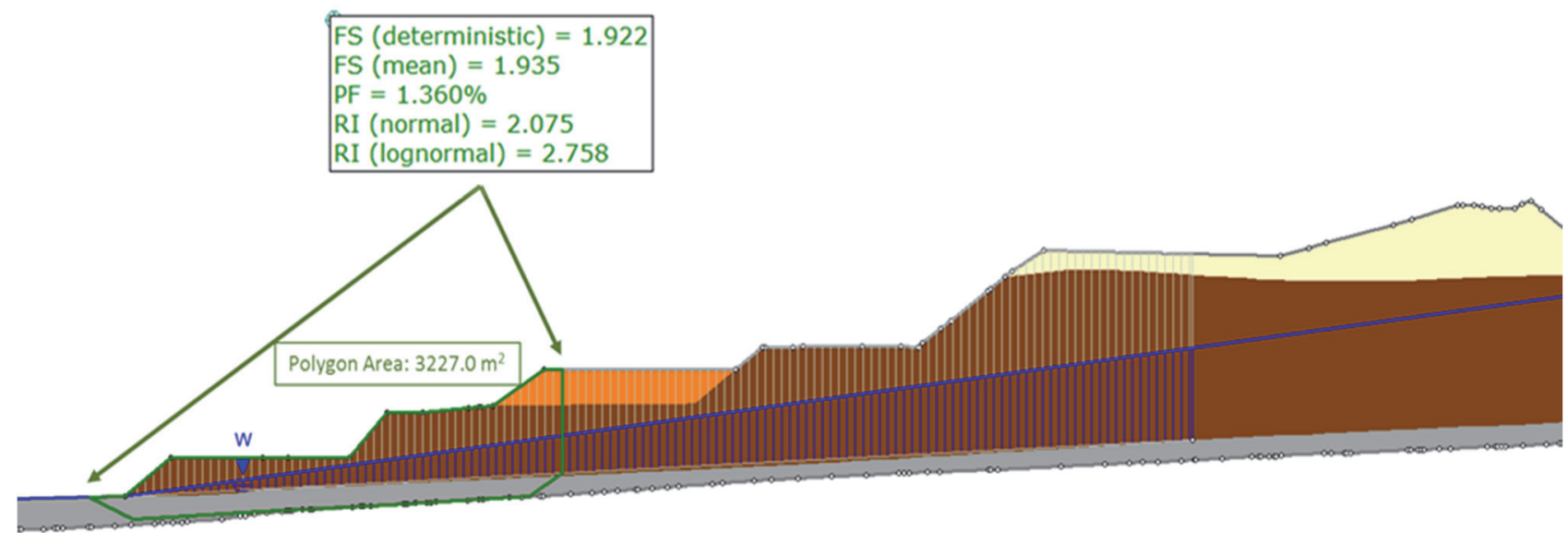

Figure 5 Derived slope stabilisation measures 
Table 4 Calculation of the Mine Geotechnical Risk Index at incorporating slope stabilisation measures risk sector 2

\begin{tabular}{|c|c|c|}
\hline Parameters & All domains & Explanatory notes \\
\hline $\mathrm{PF}$ & $1.36 \%$ & Calculated PF (Figure 5) \\
\hline Area $\left(\mathrm{m}^{3} / \mathrm{m}\right)$ & 3,227 & Cross-sectional area of critical failure (Figure 5) \\
\hline$C_{f}$ & 44 & Consequence factor ( $\mathrm{PF} \times$ area) \\
\hline$P C_{t}$ & 0.25 & $\begin{array}{l}\text { Based on an annualised probability of malfunctioning of the } \\
\text { dewatering infrastructure }\end{array}$ \\
\hline$I_{f}$ & 0.15 & Revised, based on the reduction in volume of failure and $\mathrm{Cf}$ \\
\hline$S_{f}$ & 0.5 & $\begin{array}{l}\text { Annualised likelihood of drainage malfunction increases as no } \\
\text { maintenance is undertaken during the closure phase }\end{array}$ \\
\hline MGRI & 0.8 & \\
\hline Delta & $<0 \%$ increase & \\
\hline
\end{tabular}

Whilst these slope stabilisation measures result in a notable reduction in the resultant risk profile for the section of slope under consideration, the cost of implementation of these measures is high, and therefore needs to be carefully tailored in their employment. Specifically, it is important that these stabilisation measures are employed within the most critical geotechnical sections (subdomains) of the risk sector.

As outlined earlier in the paper, the attribution of the respective risk sectors was independent of geotechnical considerations (i.e. geology, phreatic conditions, coal joint orientations or interseam clay strengths). It was based purely on the risk, likelihood and consequence associated with a potential slope instability affecting the serviceability of the adjacent piece of infrastructure and potentially members of the public.

Hosted within this risk sector (risk sector 2) are a number of geotechnical (sub) domains, each with varying material strengths, orientation and geometry of the underlying interseam and jointing patterns within the coal mass. Accordingly the calculated buttress volume and phreatic gradient to maintain a FS of 2.0 and result in a tolerable level of risk (i.e. MGRI variation) will need to be adjusted to cater for the geotechnical variations across this risk sector.

To this end, an MGRI risk map was created for risk sector 2, as presented in Table 5, which implicitly incorporated the buttress and drainage management protocols so as to evaluate whether these measures continue to remain applicable across the remainder of the sector when considering the variation in geotechnical conditions.

Accordingly, the authors created a sector risk map which considered the changing (i.e. rising) pit lake levels over the course of the 10 year rehabilitation period. Noting that upon reaching the full pit lake, the entire slope sector is submerged, resulting in a significant counterweight providing a substantial resisting force against block sliding. This risk map is useful is assessing where, and more importantly when, supplementary geotechnical management measures need to be employed across the respective areas within the slope (risk) sector to ensure that the levels of risk increase continue to remain within acceptable tolerances. 
Table 5 Mine Geotechnical Risk Index risk map - risk sector 2

\begin{tabular}{|c|c|c|c|c|c|}
\hline $\begin{array}{l}\text { Geotechnical } \\
\text { subdomain }\end{array}$ & $\begin{array}{l}\text { Starting pit } \\
\text { lake (year } 0 \text { ) }\end{array}$ & $\begin{array}{l}25 \% \text { pit Lake } \\
(0<\text { year }<3)\end{array}$ & $\begin{array}{l}50 \% \text { pit Lake } \\
(3<\text { year<7) }\end{array}$ & $\begin{array}{l}75 \% \text { pit Lake } \\
(7<\text { year<10) }\end{array}$ & $\begin{array}{l}\text { Full pit lake } \\
\text { >year } 10\end{array}$ \\
\hline 1 & & $\leq 0 \%$ & $>29 \%$ & $>29 \%$ & $\leq 0 \%$ \\
\hline 2 & & $\leq 0 \%$ & $>29 \%$ & $>29 \%$ & $\leq 0 \%$ \\
\hline 3 & & $\leq 0 \%$ & $>29 \%$ & $>29 \%$ & $\leq 0 \%$ \\
\hline 4 & & $\leq 0 \%$ & $>29 \%$ & $>29 \%$ & $\leq 0 \%$ \\
\hline 5 & Base case & $\leq 0 \%$ & $\leq 0 \%$ & $>29 \%$ & $\leq 0 \%$ \\
\hline 6 & & $>29 \%$ & $>29 \%$ & $>29 \%$ & $\leq 0 \%$ \\
\hline 7 & & $14 \%$ & $\leq 0 \%$ & $>29 \%$ & $\leq 0 \%$ \\
\hline 8 & & $\leq 0 \%$ & $\leq 0 \%$ & $\leq 0 \%$ & $\leq 0 \%$ \\
\hline 9 & & $\leq 0 \%$ & $>29 \%$ & $\leq 0 \%$ & $\leq 0 \%$ \\
\hline
\end{tabular}

Table 5 provides useful guidance to the mine owners to enable the consideration of the following points:

1. Geotechnical subdomain 8 , was used as the basis for modelling as presented in Figures 4 and 5.

2. There are two subdomains, 6 and 7 in particular, where the proposed buttress and drainage measure do not result in keeping the elevated risk levels within the nominated criteria. These two domains will need the drainage and buttress dimensions to be augmented beyond those modelled in Figure 5 (i.e. larger buttress, and additional sub-horizontal drain holes).

3. Between years 3 and 7 , the risk profile increases beyond the tolerable threshold in comparison to the starting pit lake level across nearly all of the domains, bar domain 8 , which was the subject model in Figures 4 and 5.

4. The above point (point 3 ) is noteworthy as there is a possibility that the slope management measures employed at the start of the rehabilitation process may cease to remain effective over the planned course of mine closure. This, therefore, provides some degree of insight to the mine management, so that consideration can be given to the following:

a. Plan for the supplementary installation of additional slope reinforcement measures after year three. This would necessitate a contingency budget being planned for and appropriately quarantined, and part of the closure and rehabilitation spend, say between the mine and the owners/operators of the piece of infrastructure.

b. It demonstrates that the 4 year elevated risk period corresponds to the pit lake level rising between $25 \%$ and $75 \%$ of the final level. The mine could consider supplementary lake filling protocols to accelerate the achievement of the $75 \%$ of final lake level. These measures may involve consideration of say the carefully planned diversion of treated effluent, surface water runoff, etc.

c. NB - any such measures would obviously have to be carefully evaluated with due consideration to other factors such as water quality and the broader environmental considerations. 


\section{Conclusion}

This paper has highlighted the challenges that can be faced by geotechnical practitioners when dealing with defining acceptable risk and undertaking technical assessments in the complex space of mine closure where social and natural scientific approaches to acceptable risk can be challenging to gauge, let alone quantify. A key aim that the authors intended to demonstrate via the case study was how the developed metric, the MGRI, can be employed in such settings and provide mine owners with an objective approach to rationalising the employment of post-closure geotechnical management.

Whilst the authors acknowledge that more work and refinement on the calculation factors need to be undertaken, it provides a basis for consideration by other practitioners facing similar challenges. The authors recommend caution in applying this process without the benefit of careful forethought in relation to the consequences of instability and the underlying causative/contributory factors. It is the authors' intent to further refine the MGRI approach in a number of settings to evaluate its robustness in future applications.

\section{$5 \quad$ Acknowledgement}

The authors thank GHD for providing the resources and modelling software required to draft this paper, as well as Ms Rebecca Turnbull for editing this publication.

\section{References}

Ágústsson, K, Jóhanneson, T, Sauermoser, S, Sigurđsson, Hó \& Jensen, EH 2003, Hazard Zoning for Bíldudalur, Vesturbyggð, Report 03034, Icelandic Meteorological Office, Reykjavík, viewed 6 February 2019, http://www.vedur.is/snjoflod/haettumat/ bi/bi_tech.pdf

Ammann, WJ 2005, 'Natural hazards: risk concept and integral risk management', in WJ Ammann, S Dannenmann \& L Vulliet (eds), Proceedings of RISK21 - Coping with Risks due to Natural Hazards in the 21st Century, A.A. Balkema, Rotterdam.

Australian Geomechanics Society 2000, Landslide Risk Management Concepts and Guidelines, Australian Geomechanics Society, Perth.

Bell R, Glade, T \& Danscheid M 2005, Risks in Defining Acceptable Risk Levels, University of Bonn, Bonn.

Borter, P 1999, 'Risikoanalyse bei gravitativen naturgefahren: methode', Umwelt-Materialien, no. 107/I.

Brown, T \& Booth, A 2009, 'Risk management', in J Read \& P Stacey, Guidelines for Open Pit Slope Design, CSIRO Publishing, Collingwood, pp. 382-400.

Call, RD 1992, 'Slope stability', in HL Hartman (ed.), SME Mining Engineering Handbook, vol. 1, pp. 881-896.

Chowdhury, RN 1992, 'Probabilistic risk analysis in geomechanics and water engineering', in RN Chowdhury (ed.), Geomechanics and Water Engineering in Environmental Management, A.A. Balkema, Rotterdam.

Geotechnical Engineering Office 1997, Landslides and Boulder Falls from Natural Terrain: Interim Risk Guidelines, GEO report no. 75. Geotechnical Engineering Office, Kowloon.

Glade, T, Anderson, MG \& Crozier, MJ 2005, Landslide Hazard and Risk, John Wiley \& Sons, Chichester.

Harr, ME 1977, The Mechanics of Particulate Media: A Probabilistic Approach, McGraw-Hill Book Company, New York, p. 543.

Harr, ME 1987, Reliability Based Design in Civil Engineering, McGraw-Hill Book Company, New York, p. 290.

Hoek, E \& Bray, JW 1974, Rock Slope Engineering, 3rd edn, Institution of Mining and Metallurgy, London, pp. $150-224$.

Hoek, E \& Brown, ET 1997, 'Practical estimates of rock mass strength', International Journal of Rock Mechanics and Mining, vol. 34, no. 8, pp. 1165-1186.

IUGS Working Group on Landslides - Committee on Risk Assessment 1997, 'Quantitative assessment for slopes and landslides - the state of the art', in DM Cruden \& R Fell (eds), Proceedings of the Workshop on Landslide Risk Assessment, A.A. Balkema, Rotterdam, pp. 3-12.

Jóhannesson, T \& Ágústsson, K 2002, Hazard Zoning for Debris Flows, Rockfall, Slushflows and Torrents and Slushflows Mixed with Soil in Steep Slopes, report TóJ/Kri-2002/01, Icelandic Meteorological Office, Reykjavík, in Icelandic

Jónasson, K, Sigurdsson, SP \& Arnalds, P 1999, Estimation of Avalanche Risk, report VÍ-R99001-ÚR01, Icelandic Meteorological Office, Reykjavík.

Lee, EM \& Jones, DKC 2004, Landslide Risk Assessment, Thomas Telford, London.

Lilly, PA 1982, A General Definition of Excavation Reliability and its Application in Mining Engineering, Western Australia School of Mines, Kalgoorlie.

Lilly, PA 2000, The Minimum Total Cost Approach to Optimise Pit Slope Design, Western Australia School of Mines, Kalgoorlie.

Malone, AW 2005, 'The story of quantified risk and its place in slope safety policy in Hong Kong', in T Glade, MG Anderson \& M Crozier (eds), Landslide Hazard and Risk, John Wiley \& Sons, Chichester.

Martin, DC \& DR, Piteau 1978, 'Select berm width to control local failure', Engineering and Mining Journal, June 1978, pp. 161-164. McMahon, BK 1985, 'Geotechnical design in the face of uncertainty', Australian Geomechanics News, no. 10. 
Narendranathan, S 2009, 'Fundamentals of probabilistic slope design and its use in pit optimization', Proceedings of the 43rd US Rock Mechanics Symposium \& 4th US - Canada Rock Mechanics Symposium, American Rock Mechanics Association, Alexandria.

The Ministry of the Environment 2000, Reglugerð nr. 505/2000, Reglugerð um Hættumat Vegna Ofanflóða, Flokkun og Nýtingu Hættusvæða og gerð Bráðabirgðahættumats (Regulation on hazard zoning for avalanches, debris flows and rockfall, the usage of hazard zones, and the making of preliminary hazard zoning), viewed 16 August 2018, https://www.reglugerd.is/reglugerdir/allar/nr/505-2000

Xu, D \& Chowdhury, RN 1999, 'Probabilistic analysis of structured rock slopes - several methods compared', Slope Stability Engineering, A.A. Balkema, Rotterdam. pp. 1089-1094.

Xu, D, Lilly, PA \& Walker, PA 2000, 'Stability and risk assessment of pit walls at BHP Iron Ore's Mt Whaleback mine', Proceedings of GeoEng2000: An International Conference on Geotechnical and Geological Engineering, Technomic Publishing Co., Lancaster. 